\title{
Health Services Utilization and Health Status of Insured versus Uninsured Nigerian Children with Sickle Cell Disease
}

\author{
Auwal Sani Salihu1, Abdullahi Shehu Umar² \\ ${ }^{1}$ Department of Psychiatry, Bayero University, Kano/Aminu Kano Teaching Hospital, Kano, Nigeria \\ ${ }^{2}$ Department of Paediatrics, Bayero University, Kano/Aminu Kano Teaching Hospital, Kano, Nigeria \\ Email: auwal01@yahoo.com
}

Received 22 June 2016; accepted 17 July 2016; published 20 July 2016

Copyright (C) 2016 by authors and Scientific Research Publishing Inc.

This work is licensed under the Creative Commons Attribution International License (CC BY). http://creativecommons.org/licenses/by/4.0/

(c) (i) Open Access

\section{Abstract}

Introduction: Nigeria accounts for 150,000 infants born with the Sickle Cell Disease (SCD) every year. Children with SCD are affected by the deleterious effect of user fees which reduces affordability and utilization of health services. Evidences supported that institutionalized health insurance increases intensity of utilization. Methodology: The study was conducted at AKTH, Kano, and north-western, Nigeria. The study was retrospective comparative cross-sectional study. 100 patients were enrolled, 50 for each arm. Paediatric SCD clinic outpatients' records and a specialty designed form containing the variables of interest were used. Data were analysed using Minitab 16. Proportions, percentages, tables, charts and chi squared test were used to compare the two groups. Result: The study found no association between the two groups in the likelihood of being insured based on age $\left(\chi^{2}=1.478\right)$, gender $\left(\chi^{2}=0.224\right)$ and dwellings $\left(\chi^{2}=0.062\right)$. On health services utilization and insurance status, the study revealed that follow up clinic visits, unscheduled clinic visits and emergency room visits were more likely among the insured group compared to the uninsured group. While the health status and insurance status of the two groups over 12 months period showed a significant association with the insured more likely to have improved health status compared to uninsured $\left(\chi^{2}=28.019, p=0.0001\right)$. Similarly, health status and health services utilization were significantly associated with insurance status $\left(\chi^{2}=12.191, p=0.002\right)$. Conclusion: The insurance status of children with SCD is associated with their health services utilization and health status. However, age, gender and dwellings were not associated with insurance status of children with SCD. Therefore, when expanding insurance coverage (NHIS) among children with SCD considerations have to be given to increase health services utilization and resultant improvement in health status as these have the potential of reducing morbidity and mortality among children with SCD. 
Keywords

Sickle Cell Disease, Nigeria, Health Service Utilization, Health Status, Health Insurance

\section{Introduction}

Sickle Cell Disease (SCD) is the most prevalent genetic disorder in the world Health Organization's (WHO) African Region [1]. Up to 75\% of all patients with SCD live in sub-Saharan Africa and Nigeria alone accounts for 150,000 infants born with the disease every year [2]. It has been estimated that SCD results in the annual loss of several millions of Disability-Adjusted Life Years (DALYs) particularly in the developing countries [3].

Children with SCD often experience unexpected, intermittent, and life threatening complications requiring frequent utilization of health resources [4]. However, the deleterious effect of user fees reduces affordability and utilization of drugs, and health services in general especially among vulnerable group such us children [5]. Evidences from countries that have institutionalized national health insurance reported increased intensity of utilization [6] [7]. Study from North Carolina, USA reported that publicly insured children were more likely to have emergency department visit than uninsured children [8]. Conversely, uninsured persons more often forgo or delay medical services including preventive care compared with those who have health insurance [9].

The National Health Insurance Scheme (NHIS) in Nigeria aimed at universal coverage and access to adequate and affordable health care thereby improving the health status of the citizenry. This is to mitigate the rising cost of health care services as well as the inability of the government health facilities to cope with people's demand. Prior to establishment of NHIS several systems ranging from free health care purchase, out-of-pocket purchase and retainer-ship have been in vogue [10]. NHIS as an institution is task with cost containment and improving health outcomes by pooling regular financial contribution of members and pays a network of providers of healthcare for defined specific set of health care services. The NHIS currently covers only public civil servants under the employment of the federal government. Contribution entitles the insured person, the spouse and four children under the age of 18 years access to health care. Currently NHIS has set an ambitious plan of covering 40 per cent by the year 2015 [11]. The planned expanded coverage by the NHIS set to include 42 million primary school pupils across the country. A significant number of children with Sickle Cell Disease (SCD) are within the primary school age group.

\subsection{Health Services Utilization}

Health Services utilization can be assess from two perspectives: the patient's or the physician's. The first-the patient's perspective-is somewhat subjective because it is based on patient-reported services. The second perspective is more objective, because it hinges on volume of medical services offered by physicians to patients and recorded in databases. It is this perspective that will be explored in this study. Measure of services utilization, from the physician's perspective, is often based on economic indicators based on volume, such as number of hospitalizations, number of medical acts, number of patients and number of visits [12] [13].

\subsection{Health Services Utilization, Health Insurance and Children with Sickle Cell Disease}

Children with SCD often experience unexpected, intermittent, and life threatening complications requiring frequent utilization of health resources [4]. However, the deleterious effect of user fees reduces affordability and utilization of drugs, and health services in general especially among vulnerable group such us children [5]. Evidences from countries that have institutionalized national health insurance reported increased intensity of utilization [6] [7], in a study in Baltimore USA, health insurance was found to lead to an increase in non-urgent utilization of health facilities [14]. Similarly in Taiwan, the utilization of most prenatal and intra-partum care services increased after commencement of NHIS [15]. In Nigeria Tanimola A et al. [16] reported that NHIS led to $144 \%$ increase in the utilization of health service at staff clinic of the University Teaching Hospital. A Study from North Carolina, USA reported that publicly insured children were more likely to have emergency department visit than uninsured children [8]. Conversely, uninsured persons more often forgo or delay medical services including preventive care compared with person who have health insurance [9].

It has been shown in the available literature that access to health insurance coverage is associated with in- 
crease health resources utilization [9] and improved health status. This study set out to determine for the first time in Nigeria the relationship of health services utilization and health status to insurance coverage (NHISinsured versus NHIS-uninsured) of children with SCD. The study sets out to achieve the following research objectives: 1) To explore the relationship between NHIS insurance coverage and health services utilization among insured and uninsured children with SCD. 2) To examine the relationship between NHIS-insurance coverage and health status among insured and uninsured children with SCD. 3) To determine the relationship between Health Services Utilization and Health Status of insured and uninsured Children with SCD. Findings from this study will provide evidence-based insight on expected impact of enrolling all children with SCD into the NHIS regarding their health services utilization and health status. Reliable information on health resources utilization and associated health status improvement could guide policymakers, advocacy groups and healthcare providers in making appropriate decisions concerning allocation of scarce resources in health care provision for the Nigerian children with SCD. This study focuses and gathered data from the records of NHIS insured and uninsured children (1 - 12 yrs old) with SCD attending Aminu Kano Teaching Hospital Paediatric SCD outpatients clinic. Only children (NHIS-insured and uninsured) whom have been attending the clinic for at least 6 months before the recruitment period of this study were included. Those with incomplete records or their records could not be traced were excluded from the study. The limitation of our study include: This is descriptive retrospective crosssectional study and therefore causal relationship cannot be attributed and the study relies on the available information documented in the patients' record from June 2013 to June 2014.

\section{Methodology}

AKTH is a 500-bed tertiary level facility affiliated to Bayero University, Kano (BUK) and located in Tarauni Local Govt in Kano City. The paediatrics sickle cell clinic of the hospital is housed within the specialty paediatrics specialty clinic building and is staffed by 4 consultants and 3 resident physicians. This clinic has a total pool of about 1000, with approximately 80 children (Neonates inclusive) with SCD seen each clinic day (once per week). Each patient seen for the first time or on follow up received between 1 - 12 weeks subsequent visit appointment.

\subsection{Study Design}

This is a retrospective comparative cross-sectional study.

\subsection{Sample Size Estimation}

The calculated sample size based on the objective of determining the proportion of health services utilization of insured and uninsured children with SCD was using the formula:

$$
\text { Patient per group }=p_{1}\left(1-p_{1}\right)+p_{2}\left(1-p_{2}\right) /\left(p_{2}-p_{1}\right) \times f(\alpha, \beta)
$$

where $p_{1}=0.38$ (38\%) [8], $p_{2}=0.53(53 \%), f(\alpha, \beta)=10.590 \%$ power and $5 \%$ confidence interval.

Therefore, patient per group $=0.38(1-0.38)+0.53(1-0.53) / 0.53-0.38 \times 10=0.38(0.62)+0.53(0.47) /$ $0.15 \times 10=0.2356+0.2491 / 0.15 \times 10.5=356$. However, the minimum sample size is more than the number of the insured children with SCD to be included in the study. Thus, a formula for calculating sample size for finite population was used to reduce the sample size. $n_{f}=n / 1+{ }^{n} / N$, Where $n=$ Minimum sample size calculated $=356$. $n_{f}$ = sample of finite population, $d=$ degree of precision/margin of error $=0.05, N=$ size of population $=51$.

Therefore, $n_{f}=356 / 1+356 / 51=356 / 7.98=44.6$, adding $10 \%$ attrition rate was added making it $44.60+4.46$ $=50.06 \approx 50$.

\subsection{Inclusion Criteria}

1) Children between the age of 1 to 12 years who have NHIS coverage and attending Paediatric SCD Clinic in the preceding 12 months.

2) Children between the age of 1 to 12 years who did not have NHIS coverage (or Private) and attending Paediatric SCD Clinic in the preceding 12 months.

\subsection{Sampling Technique}

Simple Random Sampling method was used to draw 50 out of 51 children with SCD who are NHIS insured that 
satisfied the inclusion criteria of this study.

Similar, among those children who are not NHIS insured 714 satisfied the criteria for inclusion in the study. Simple Random Sampling was used draw 50 among them.

\subsection{Instruments}

1) Paediatric SCD clinic outpatient attendance registers.

2) Form designed for record the variables of each participant from his/her hospital record. Variables recorded include socio-demographic viz. age, gender, ethnicity, and Parent occupation, Insurance Status, No of hospital visits, No of admission, No of unscheduled visits, Emergency room visits and Physician opinion on patient health status.

\subsection{Protocol and Data Analysis}

Data from the records of the one hundred randomly selected patients, fifty from each arm of insured and uninsured children with SCD was recorded on the specially designed form. Socio-demographic information which include age, gender and place of residence as well as insurance status, number of hospital admission, no of unscheduled visits, emergency room visits and physician's opinion on patient health status over the past one year was recorded. Patients with incomplete records were excluded. They were few and all were among the uninsured. Data was analysed using Minitab 16. Proportions, percentages, tables, charts, chi squared test were used to compare the two groups in the analysis.

\subsection{Ethical Approval}

The research was approved by the research ethics committee of the Aminu Kano Teaching Hospital, Kano.

\subsection{Declaration of Interest}

This research did not receive any specific grant from funding agencies in the public, commercial, or not-forprofit sectors.

\section{Result}

\subsection{Demographic Factors and Insurance Status}

One hundred patients' records were analysed. Fifty from each of the studied-groups insured and uninsured children with Sickle Cell Disease. Among the insured, $16 \%$ were males and 34\% were females while among the uninsured 21\% were males and 29\% were females (Table 1 \& Figure 1). There were slightly more females among the insured than uninsured. There was no significant difference between the genders in the likelihood of being insured $\left(\chi^{2} 1.073, \mathrm{p}=0.300\right)$. Majority of the patients among the insured and uninsured groups were within the age group of $1-6$ years, 32\% and 26\% respectively while the rest were within the age group of 7 - 12

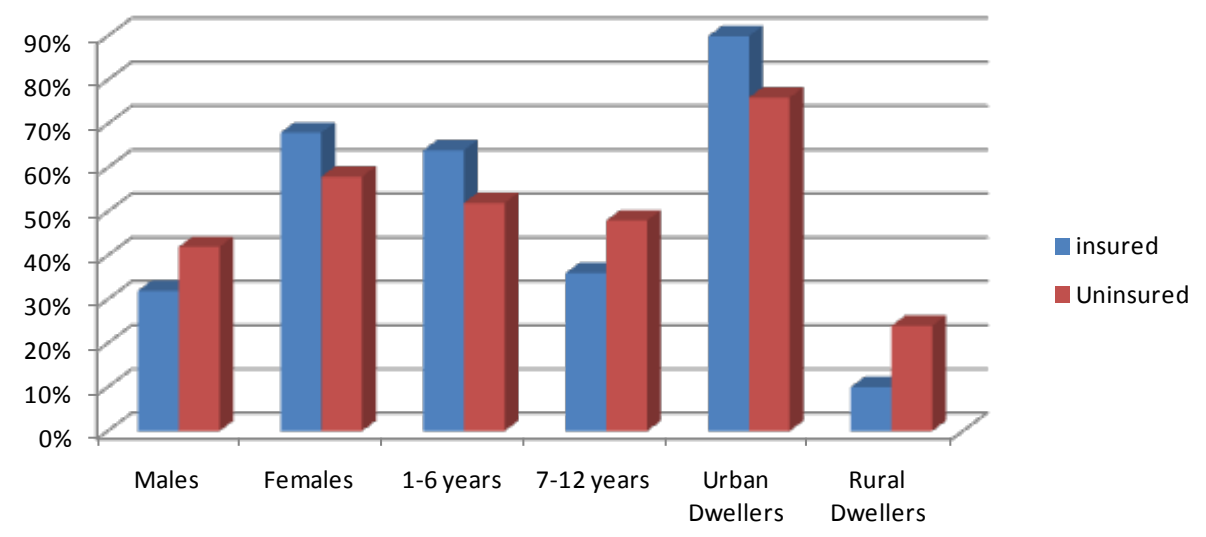

Figure 1. Socio-demographic characteristics of the patients. 
Table 1. Relationship between socio-demographic factors of the patients and insurance status.

\begin{tabular}{|c|c|c|c|c|}
\hline Socio-demographic factors & Insured $f(\%)$ & Uninsured $f(\%)$ & $\chi^{2}$ & p-value \\
\hline Males & $16(16)$ & $21(21)$ & 1.073 & 0.300 \\
\hline Females & $34(34)$ & $29(29)$ & & \\
\hline Total & $50(50)$ & $50(50)$ & & \\
\hline 1 - 6 years & $32(32)$ & $26(26)$ & 1.478 & 0.224 \\
\hline 7 - 12 years & $18(18)$ & $24(24)$ & & \\
\hline Total & $50(50)$ & $50(50)$ & & \\
\hline Urban & $45(45)$ & $38(38)$ & 3.473 & 0.062 \\
\hline Rural & $5(5)$ & $12(12)$ & & \\
\hline Total & $50(50)$ & $50(50)$ & & \\
\hline
\end{tabular}

years old. Urban dwellers were more and constitute $45 \%$ among the insured compared to $38 \%$ of the uninsured group. However, there were no statistically significant difference between the two groups in their likelihood of being insured based on their age $\left(\chi^{2}=1.478, \mathrm{p}=0.224\right)$ or dwellings $\left(\chi^{2}=3.473, \mathrm{p}=0.062\right)$.

\subsection{Health Services Utilization and Insurance Status}

There were a total of 1141 hospital visits by the subjects during the 12 months period under investigation. The insured group had a total of 656 (57.5\%) visits while the uninsured group had 485 (42.5\%) visits. The difference between the two groups in total number of visits during the period was statistically significant $\chi^{2}=6.684$, $p$ value $=0.035)$. Regular follow up visits constitute the greater portion of the total visits $(63.7 \%)$. Both follow up clinic and Un-schedule clinic visits were more among the insured compared to uninsured. Visits to the emergency room by the insured group (8.5\%) was twice as many as in the uninsured group (4.1\%) (Table 2).

\subsection{Health Status and Insurance Status}

With respect to health status of the two groups during the period of 12 months, there were 7 times as many insured $(28 \%)$ in good health compared uninsured (4\%). Thirteen of uninsured children were assessed from the records as having poor health status compared to only 3 among the insured. Overall, there was a statistically significant difference between the insured and the uninsured in improved health status as the insured were more likely to have improved health status compared to uninsured $\left(\chi^{2}=28.019\right.$, p value $\left.=0.0001\right)$ (Table 3).

\subsection{Health Status, Health Services Utilization and Health Insurance}

There was an association between health status and health resources utilization. There were twice $5.3 \%$ compared to $11.3 \%$ ) the number of visits to health care providers among the uninsured with poor health status compared to those with good health status. Similarly, among the insured those with good health status utilized health services fewer (8.2\% compared to $10.3 \%)$ than those with poor health. There was a statistically significant difference between the health status of the insured and those uninsured $\left(\chi^{2}=12.191\right.$, $p$ value $\left.=0.002\right)$ (Table 4$)$.

\section{Discussion}

In general, it was reported in the available literature that health insurance coverage is associated with increase health resources utilization [8]. In this study, health services utilization of insured children with SCD was found to be significantly higher than those children without health insurance cover. The insured had slightly more follow up clinic visits, more unscheduled clinic visits and twice more emergency room visits compared to their counterpart, the uninsured. This findings were similar to that of [16] Tanimola et al. who reported $144 \%$ increase in the utilization of health service at university of Ilorin teaching hospital staff clinic and that of [8] reported increased likelihood of insured children visiting emergency room more than the uninsured children. The preponderance of emergency room visits among the insured may be due to absence of the deleterious effect of 
Table 2. Relationship of health services utilization and insurance status.

\begin{tabular}{cccc}
\hline Health services utilization & Insured & Uninsured & Total \\
\hline Follow up clinic visits & $410(35.9)$ & $317(27.8)$ & $727(63.7)$ \\
Un-schedule clinic visits & $149(13.1)$ & $121(10.6)$ & $270(23.7)$ \\
Emergency room visits & $97(8.5)$ & $47(4.1)$ & $144(12.6)$ \\
Total & $656(57.5)$ & $485(42.5)$ & $1141(100.0)$ \\
\hline
\end{tabular}

$\chi^{2}=6.684, \mathrm{p}$ value $=0.035$.

Table 3. Relationship of heath status and insurance status of the patients.

\begin{tabular}{cccccc}
\hline Health status & Insured $\boldsymbol{f}(\boldsymbol{\%})$ & Uninsured $\boldsymbol{f}(\mathbf{\%})$ & Total & $\chi^{2}$ & p-value \\
\hline Good & $28(28)$ & $4(4)$ & $32(32)$ & 9.000 & $<0.0001$ \\
Fair & $19(19)$ & $33(33)$ & $52(52)$ & 1.885 & $<0.0001$ \\
Poor & $3(3)$ & $13(13)$ & $16(16)$ & 3.125 & $<0.0001$ \\
Total & $50(50)$ & $50(50)$ & $100(100)$ & & \\
\hline
\end{tabular}

$\chi^{2}=28.019$, p value $=0.0001$.

Table 4. Relationship of health status and health services utilization.

\begin{tabular}{cccc}
\hline \multirow{2}{*}{ Health status } & \multicolumn{2}{c}{ Health services utilization } & Total \\
\cline { 2 - 3 } & Insured & Uninsured & $154(13.5)$ \\
Good & $93(8.2)$ & $61(5.3)$ & $740(64.9)$ \\
Fair & $445(39.0)$ & $295(25.9)$ & $247(21.6)$ \\
Poor & $118(10.3)$ & $129(11.3)$ & $1141(100.0)$ \\
Total & $656(57.5)$ & $485(42.5)$ & \\
\hline
\end{tabular}

$\chi^{2}=12.191, \mathrm{p}$ value $=0.002$.

user fees on affordability of health services and drugs [5].

This study revealed a significant association between insurance status and better health state. Those children with SCD who were insured had 7 times more likelihood to be in good state of health compared to uninsured ones. There are about $28 \%$ of insured children with SCD which the physician assessed to have had good health status compared to only $4 \%$ among the uninsured.

Health status and health services utilization was found to be associated $\left(\chi^{2}=12.191\right.$, $\mathrm{p}$ value $\left.=0.002\right)$ in this study, as there were twice the number of health services visits among the uninsured with good health status compared to those with poor health status. A study by O'Hara et al. [17] reported similar relationship, though not only among children with SCD but among diverse group of patients.

Socio-demographic factors that were considered in this study showed no statistically significant association with insurance status. This differed from findings in some earlier studies [12]. This could be explained by the differences in the type of insurance i.e. public or private. In most of those studies, the participants were on private health insurance unlike the patients in this study who were on the NHIS which is a form of social health insurance currently covering only federal civil servants and their dependents. Thus, the patients in this study do not differ much socio-demographically.

\section{Conclusion}

Children with sickle cell disease are affected by the deleterious effect of user fees which reduces affordability and utilisation of health services. Evidences supported that institutionalised health insurance increases intensity of health services utilisation. We used paediatric SCD clinic outpatients' records to examine the effect of health insurance on the health services utilisation and health status of insured compared to uninsured children with 
SCD. The insurance status of children with SCD is associated with their health services utilisation and health status. However, age, gender and dwellings were not associated with insurance status of children with SCD. Therefore, when expanding insurance coverage (NHIS) among children with SCD considerations have to be given to increase health services utilization and resultant improvement in health status as these have the potential of reducing morbidity and mortality among children with SCD.

\section{References}

[1] World Health Organization (2011) Sickle Cell Disease and Other Haemoglobin Disorders, Fact Sheet No 308. www.who.int/mediacentre/factsheets/fs308/en/

[2] David, C.R., Thomas, N.W. and Mark, T.G. (2006) Sickle Cell Disease. The Lancet, 376, 2018-2031.

[3] Weatherall, D.J., Akinyaju, O., Fucheroen, S., Olieveri, N.F. and Musgrove, P. (2010) "Inherited Disorders of Haemoglobin” in Disease Control Priorities in Developing Countries. Oxford University Press, New York.

[4] Mayer, M.L., Konrad, T.R. and Dvorak, C.C. (2003) Hospital Resources Utilization among Patients with Sickle Cell Disease. Journal of Health Care for the Poor and Underserved, 14, 122-135. http://dx.doi.org/10.1353/hpu.2010.0834

[5] Blanchet, N.J., Fink, G. and Osei-Akoto, I. (2012) The Effect of Ghana’s National Health Insurance Scheme on Health Care Utilisation. Ghana Medical Journal, 46, 76-84.

[6] Sanusi, R.A. and Awe, A.T. (2009) An Assessment of Awareness Level of National Health Insurance Scheme among Health Care Consumers in Oyo State, Nigeria. The Social Science, 2, 143-148.

[7] Sulzbach, S., Garslong, B. and Owusu-Banahene, G. (2005) Evaluating the Effect of National Health Insurance Act in Ghana; Baseline Report. United States Agency for International Development (USAID).

[8] Luo, X., Liu, G., Frush, K. and Hey, L.A. (2003) Health Insurance Status and Emergency Department Utilization in the United States. Paediatrics, 122, 314-319. http://dx.doi.org/10.1542/peds.112.2.314

[9] Center for Disease Control and Prevention (2010) Vital Signs; Health Insurance Coverage and Health Care Utilization, United States-2006-2009: Morbidity \& Mortality Weekly Report 1-7.

[10] Akande, T., Salauddeen, A. and Babatunde, O. (2011) The Effects of National Health Insurance Scheme on Utilization of Health Services at Unilorin Teaching Hospital Staff Clinic, Ilorin Nigeria. Health Science Journal, 5, 98-106.

[11] Adejoro, L. (2014) NHIS to Achieve 40\% Health Coverage. Executive Secretary. Daily Times, 23 January. www.dailytimes.com.ng/article/nhis-achieve-40-health-coverage-2015-says-executive-secretary

[12] Andersen, R. and Newman, J.P. (1973) Societal and Individual Determinants of Medical Care Utilization in the United States. Milbank Memorial Fund Quarterly Health Society, 51, 95-124. http://dx.doi.org/10.2307/3349613

[13] Beland, F. (1988) Utilization of Health Services as Events: An Exploratory Study. Health Services Research, 23, 295310.

[14] Speck, S.K., Peyrot, M. and Hsaw, C.W. (2003) Insurance Coverage and Health Care Consumers' Use of Emergency Departments: Has Managed Care Made a Difference? Journal of Hospital Marketing \& Public Relations, 15, 3-18. http://dx.doi.org/10.1300/J375v15n01_02

[15] Li-Mei, C., Shi, W.W. and Chung-Yi, L. (2001) The Impact of National Health Insurance on the Utilization of Health Care Services by Pregnant Women: The Case in Taiwan. Maternal and Child Health Journal, 5, 35-42. http://dx.doi.org/10.1023/A:1011345801673

[16] Tanimola, M.A., Salaudeen, A.G., Babatunde, A.O., Durowade, K.A., Agbana, B.E., Olomofe, C.O. and Aibinuomo, A.O. (2012) National Health Insurance Scheme and Its Effect on Staffs Financial Burden in a Nigerian Tertiary Health Facility? International Journal of Asian Social Science, 2, 2175-2185.

[17] O’Hara, B. and Caswell, K. (2013) Health Status, Health Insurance, and Medical Care Utilization: 2010. Household Economic Studies; Current Population Reports, P70-133RV, 1-16. 


\section{Submit or recommend next manuscript to SCIRP and we will provide best service for you:}

Accepting pre-submission inquiries through Email, Facebook, LinkedIn, Twitter, etc.

A wide selection of journals (inclusive of 9 subjects, more than 200 journals)

Providing 24-hour high-quality service

User-friendly online submission system

Fair and swift peer-review system

Efficient typesetting and proofreading procedure

Display of the result of downloads and visits, as well as the number of cited articles

Maximum dissemination of your research work

Submit your manuscript at: http://papersubmission.scirp.org/ 